\title{
Submonolayer-Pt-Coated Ultrathin Au Nanowires and Their Self- Organized Nanoporous Film: SERS and Catalysis Active Substrates for Operando SERS Monitoring of Catalytic Reactions
}

\author{
Rui Liu, ${ }^{\dagger}$ Jing-Fu Liu, ${ }^{*}{ }^{\dagger}$ Zong-Mian Zhang, ${ }^{\dagger}$ Li-Qiang Zhang, $^{\ddagger}$ Jie-Fang Sun $^{\dagger}$ Meng-Tao Sun, ${ }^{\S}$ \\ and Gui-Bin Jiang ${ }^{\dagger}$
}

${ }^{\dagger}$ State Key Laboratory of Environmental Chemistry and Ecotoxicology, Research Center for Eco-Environmental Sciences, Chinese
Academy of Sciences, Beijing 100085, China
${ }^{\ddagger}$ State Key Laboratory of Heavy Oil Processing and Department of Materials Science and Engineering, China University of
Petroleum, Beijing 102249, China
${ }^{\S}$ Beijing National Laboratory for Condensed Matter Physics, Institute of Physics, Chinese Academy of Sciences, Beijing 100190,
China

Supporting Information

\begin{abstract}
For their unique properties, core-shell bimetal nanostructures are currently of immense interest. However, their synthesis is not a trivial work, and most works have been conducted on nanoparticles. We report herein a new synthetic tactic for submonolyerPt coated ultrathin Au nanowires (NWs). Besides providing a strong electromagnetic field for Raman signal enhancing, the underlined $\mathrm{Au}$ NWs markedly enhanced the catalytic activity of Pt atoms through increasing their dispersity and altering their electronic state. The integration of excellent SERS and high catalytic activity within Au@Pt NWs enable it work as platform for catalyzed reaction study. As a proof of principle, the self-organized $\mathrm{Au} @$ Pt NWs thin film is employed in operando SERS monitoring of the $p$-nitrothiophenol reduction process. In addition to providing kinetic data for structure-activity relationship study, the azo-intermidate independent path is also directly witnessed. This synthetic tactic can be extended to other metals, thus offering a general approach to modulate the physical/ chemical properties of both core and shell metals.
\end{abstract}

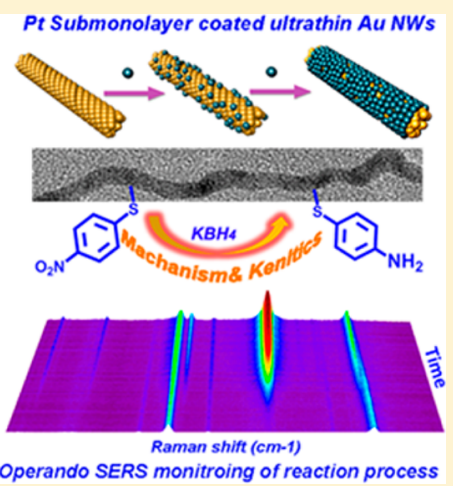

SECTION: Physical Processes in Nanomaterials and Nanostructures

\begin{abstract}
T $\mathrm{t}$ is anticipated that combining multiple phases within 1 discrete nanoscale objectives may endow nanostructures with exponentially increased potential applications. ${ }^{1-4}$ One instance is the integration of SERS (surface enhanced Raman scattering) active $\mathrm{Au}$ or $\mathrm{Ag}$ nanostructure $(>20 \mathrm{~nm})$ with catalytic active transition metals in the form of nanoshells, ${ }^{2}$ nanoisland ${ }^{3}$ or nanorespberries ${ }^{4}$ for the in situ SERS surveying of catalytic process, which has significant importance for mechanism study and catalyst formula optimization. ${ }^{2-6}$ However, for its short-range nature, the SERS performance of the core material sharply attenuated as the shell layer gets thick. Therefore, monolayer (ML) or even submonolyer shell is desirable. Meanwhile, maintaining the functionality while lowering the cost by using a smaller amount of expensive metals is also an issue of practical urgency. ${ }^{7}$ Coincidentally, for the existence of bimetal/synergetic effect, ${ }^{8}$ incorporating Au or $\mathrm{Ag}$ core is one of the most effective ways, and the formation of a monolayer or even a highly dispersed atom of catalytically active metal is a valid state-of-the art the tactic. ${ }^{9}$ For example, the durability and activity of Pt and Pd nanocatalysts in oxygen reduction, small organic molecule oxidation, as well as dehalogenation reaction is markedly improved by a $\mathrm{Au}$ core. ${ }^{3,10-13}$ Furthermore, this promoting effect is significantly
\end{abstract}

strengthened as the size of the $\mathrm{Au}$ is decreased to a critical size, ca. $5 \mathrm{~nm} .{ }^{14}$ In addition, the implementation of a small $\mathrm{Au}$ or $\mathrm{Ag}$ core also has other advantages like increased atomic utilization efficiency for shell metals. Unfortunately, for their ineffectiveness in harnessing the incident light to stimulate the electromagnetic field, $\mathrm{Au}$ or $\mathrm{Ag}$ nanoparticles with ultrasmall size $(<5 \mathrm{~nm})$ usually display limited SERS activity; however, this can be alleviated through the introduction of extra-SERS substrate. ${ }^{15}$ Additionally, among the well-documented synthetic routes for core-shell nanostructures, including epitaxial growth of shell metal on the surface of core particles, ${ }^{16,17}$ galvanic displacement or $\mathrm{Cu}$ underpotential deposition followed by galvanic displacement, ${ }^{18-20}$ controlled coreduction of metal precursors, ${ }^{21,22}$ and annealing-induced elemental diffusion inside nanoalloy, ${ }^{23,24}$ though their success is indisputable, most of them are only valid for nanoparticles with diameter of 20 to $50 \mathrm{~nm}$, and suffer from low controllability over shell thickness. It is highly desired to design new nanoarchitectures

Received: February 3, 2014

Accepted: February 27, 2014

Published: February 27, 2014 
that simultaneously possess high SERS and satisfactory catalytic performance.

Although many previous studies have reported the excellent SERS property of $\mathrm{Au} / \mathrm{Ag}$ nanowires (NWs) or NW arrays, ${ }^{25-27}$ examples of employing ultrathin Au NWs or their assembly as SERS substrates are sparse. ${ }^{28}$ Herein, we report that submonolayer Pt $(\leq 1.0 \mathrm{ML})$ coated ultrathin $\mathrm{Au}$ NWs are new SERS active highly efficient catalysts. Our study shows that $\mathrm{Au}$ NWs propose high SERS activity, which is still well retained after being coated by a Pt submonolayer. Moreover, the synthesized Au@Pt NWs, especially highly dispersed Pt-atomcoated Au NWs, display very high activity in FA oxidation and $-\mathrm{NO}_{2}$ reduction reaction, making such material an ideal platform for in situ chemical process study by SERS. As a proof of principle, Pt shell-catalyzed reduction of nitrothiophenol ( $p$ NTP) was monitored by SERS in operando conditions to study the reaction kinetics and mechanism.

Ultrathin $\mathrm{Au}$ NWs were synthesized according to our previously reported procedure. $^{29}$ Briefly, under vigorous stirring, $3 \mathrm{~mL}$ ice-cooled $\mathrm{KBH}_{4}$ solution was quickly injected into a $47 \mathrm{~mL}$ ice-cooled aqueous solution containing 0.05 mmol of $\mathrm{HAuCl}_{4}$ and $25 \mathrm{mg}$ of TX-114. After the addition of $\mathrm{KBH}_{4}$, the mixture was further stirred for $1 \mathrm{~min}$ at $0{ }^{\circ} \mathrm{C}$. For the preparation of $\mathrm{Au} @ \mathrm{Pt}$ core-shell NWs, $10.0 \mathrm{~mL}$ of a freshly synthesized $\mathrm{Au} \mathrm{NW}$ dispersion was transferred to a new flask, $0.19,0.375,0.75,1.50$, and $3.0 \mathrm{~mL}$ of ice-cold $1.0 \mathrm{mM} \mathrm{H}_{2} \mathrm{PtCl}_{6}$ solution was added into the flask dropwise under vigorous magnetic stirring, and the thickness of coating metal was $1 / 16$, $1 / 8,1 / 4 /, 1 / 2$ and 1.0 ML, respectively.

To confirm the core-shell nature of synthesized nanostructure, as well as probe the atomic geometry of the Pt atom on $\mathrm{Au}$ NWs, a combination of physical characterization techniques and electrochemical experiments were performed. Figures 1a

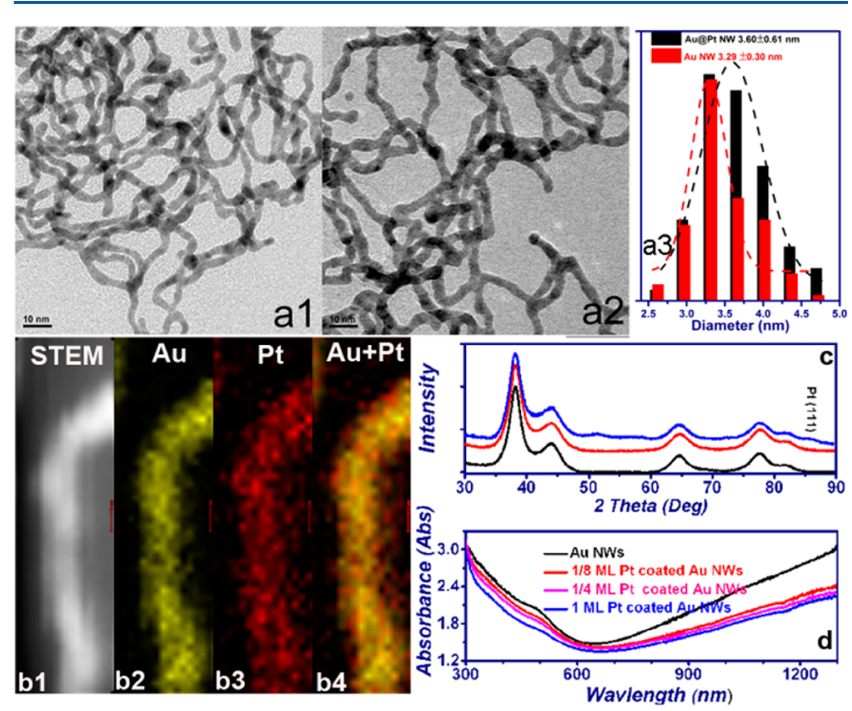

Figure 1. Characterization of $\mathrm{Au}$ and $\mathrm{Au} @ \mathrm{Pt}$ NWs by (a) highmagnification TEM, (b) HAADF-STEM-EDS mapping, (c) XRD, and (d) UV-vis-NIR spectra.

and S1 show typical highly magnified TEM images of synthesized Au@Pt NWs and Au NWs, which was employed as the starting material for Au@Pt NW synthesis. The resulting $\mathrm{Au} @$ Pt nanostructure still keeps the NWs morphology. The pristine $\mathrm{Au}$ NWs have a diameter of $3.35 \pm 0.31 \mathrm{~nm}$, while, after being coated by $1.0 \mathrm{ML}$ of $\mathrm{Pt}$, it increases to $3.66 \pm 0.61$ $\mathrm{nm}$. The increment of about $0.3 \mathrm{~nm}$ in diameter provides convincing evidence for the formation of a Pt shell. Moreover, the absence of other nanostructured objectives manifests that all added Pt was coated on $\mathrm{Au}$ NWs, and this notion is further supported by element analysis (Figure S2-S3). HAADFSTEM-EDS mapping on a single Au@Pt NW (Figure 1b) reveals that Pt uniformly distributed on the Au surface, and for its extremely thin thickness, no Pt shell that is usually observed in thick Pt layers was present. The almost identical XRD pattern for $\mathrm{Au}$ and $\mathrm{Au} @ \mathrm{Pt} \mathrm{NWs}$ again reflects the thinness of the $\mathrm{Pt}$ shell (Figure 1c), and the formation of few $\mathrm{Pt}$ nanoparticles. ${ }^{30}$ It is deserves noting that if injecting $\mathrm{H}_{2} \mathrm{PtCl}_{6}$ solution to $\mathrm{Au}$ NWs quickly, the $\mathrm{Pt}$ (311) diffraction pattern can be observed at $85.95^{\circ}$ (blue line in Figure 1c and Figure S4), suggesting the formation of separated Pt NPs, and the importance of slow addition of $\mathrm{H}_{2} \mathrm{PtCl}_{6}$. After being coated by a thin Pt layer, the optical characteristic of the resulting coreshell NWs is still dominated by the surface plasmon resonance (SPR) character of Au NWs (Figure 1d), which is essential for retaining the SERS performance of Au NWs. However, for the low light extinction coefficient and the interband transition of Pt layer, the SPR bands were severely damped, the small peak at $500 \mathrm{~nm}$ was almost completely shielded, and the absorbance in NIR is also largely reduced, confirming the existence of a $\mathrm{Pt}$ shell. $1,31,32$

XPS analysis further verified the metallic nature of Pt in $\mathrm{Au} @$ Pt NWs. Previous study revealed that ultrasmall Pt particles is prone to be oxidized. ${ }^{33}$ Our result also shows that in Pt NWs with diameters of $2.2 \mathrm{~nm}$, only $58 \%$ of the Pt exists as $\mathrm{Pt}(0)$. However, after being deposited on $\mathrm{Au} \mathrm{NW}$ surfaces, most $\mathrm{Pt}$ atoms exist as metallic Pt (70-80\%) (Figure S5-7), indicating that the ligand effect of $\mathrm{Au}$ atoms markedly altered the electronic state and heightened the antioxidation capacity of $\mathrm{Pt}$ atoms. Additionally, the binding energy of $\mathrm{Pt} 4 \mathrm{f}$ electrons downshift about 0.2 to $0.6 \mathrm{eV}$, signaling the charge transfer from $\mathrm{Au}$ to neighboring $\mathrm{Pt}$ atoms, which is a possible driving force for the formation of a Pt layer on the Au surface, rather than separated Pt nanostructures. This charge transfer between $\mathrm{Au}$ and Pt may enhance the catalytic performance of $\mathrm{Au} @ \mathrm{Pt}$ NWs, i.e., alert the binding strength between reactants and $\mathrm{Pt}$ atom.

To deeply visualize the atomic geometry of the Pt layer, SERS and electrochemistry experiments were performed on the synthesized Au@Pt NWs. As it displays adsorbing metaldependent SERS spectrum, ${ }^{34}$ 2,6-dimethylphenylisocyanide (2,6-DMPI) was employed to reveal the core-shell nature of the synthesized NWs, as well as verify their good SERS performance. As shown in Figure 2, Au and Au@Pt NWs display satisfactory SERS activity, which is about 200 times more intense than that on Pt NWs (excited by $532 \mathrm{~nm}$ laser). Such good SERS performance is attributed to the SERS hotspots like nanowells and nanojunctions formed by piling up of NWs. ${ }^{35}$ Given that Pt nanostructures show limited SERS activity in the visible region, and are almost inactive in the nearinfrared region, this good SERS performance must be "borrowed" from the underlying Au NWs (Figure S8). ${ }^{2}$ In accordance with damped SPR bands shown in Figure 1d, the SERS signal from Au@Pt NWs was weaker than that on $\mathrm{Au}$ NWs (see infrared for quantitative data and detained reason). Additionally, after being adsorbed on Au NWs, the $\nu_{\mathrm{NC}}, 9 \mathrm{~b}$ (B2) and $\nu_{\mathrm{C}-\mathrm{NC}}$ bands for 2,6-DMPI relocated from 2121, 1172, and 642 to 2168,1175 , and $659 \mathrm{~cm}^{-1}, 36$ respectively. This large blue-shift of $\nu_{\mathrm{NC}}$ and $\nu_{\mathrm{C}-\mathrm{NC}}$ band associates with the strong 


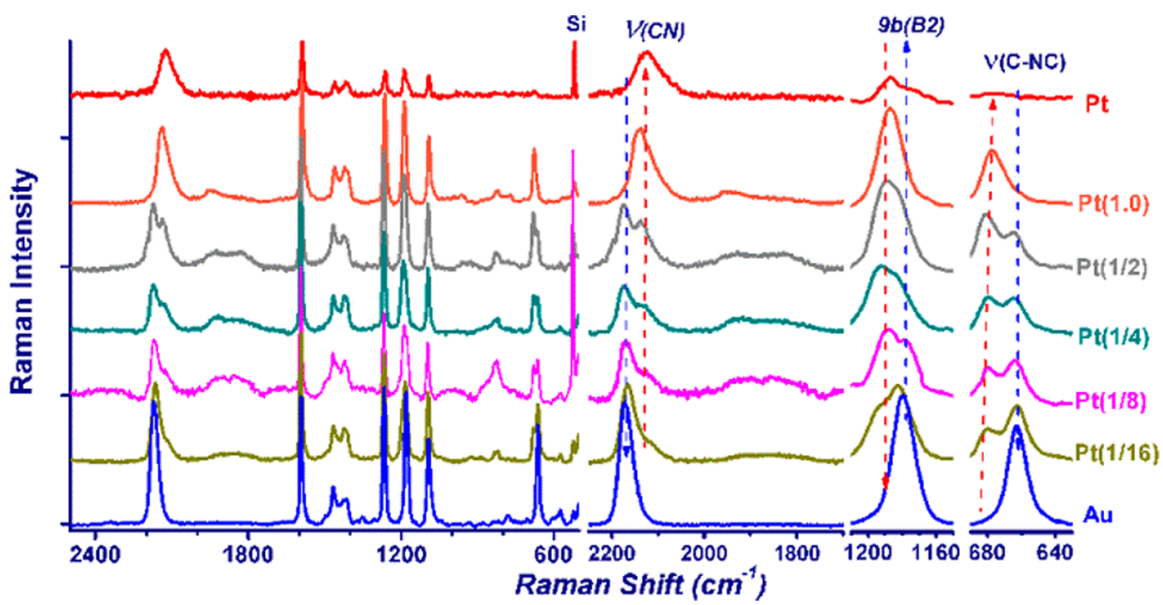

Figure 2. SERS spectra of 2,6-DMPI bounded on synthesized Au, Au@Pt NWs (785 nm laser), and Pt NW film ( 532 nm laser and magnified by 100 for comparison).
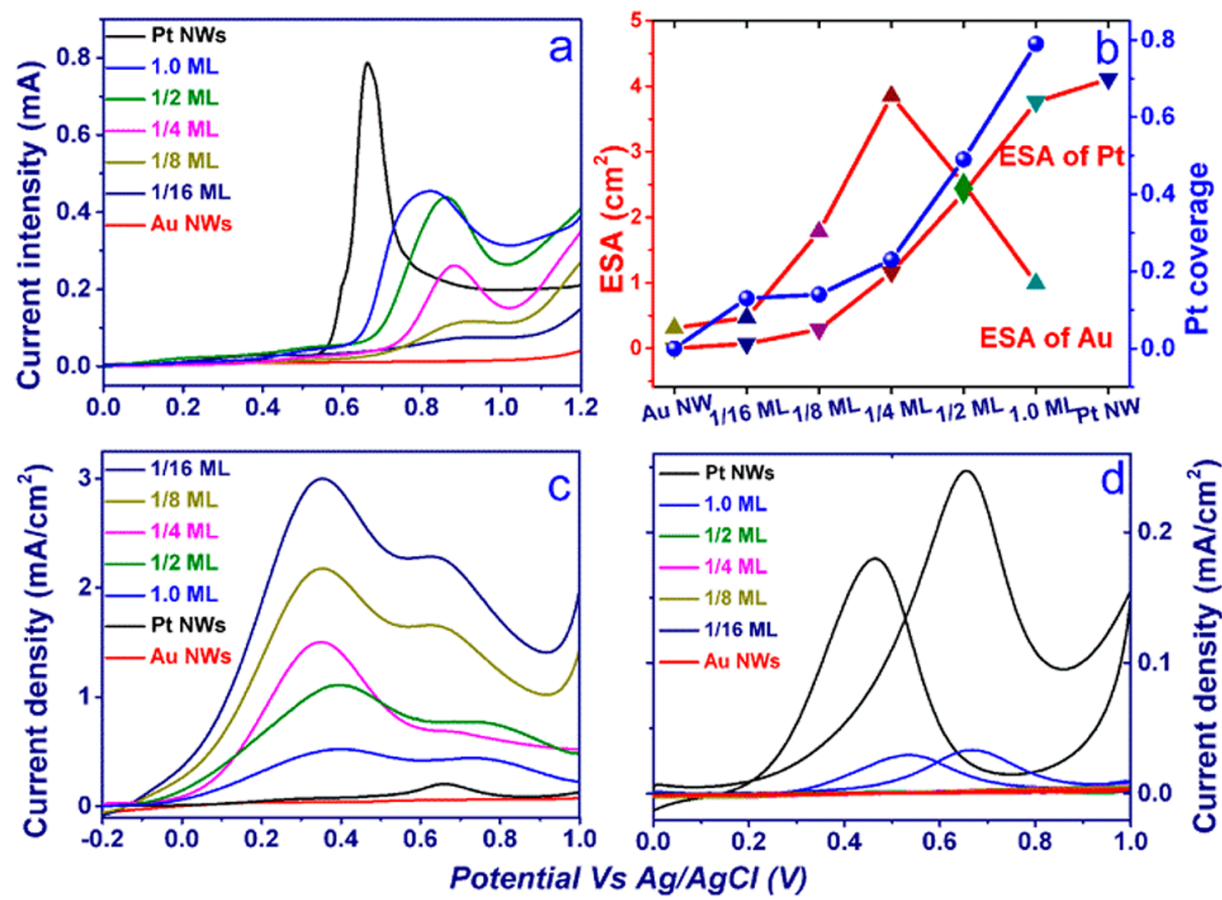

Figure 3. Probe of the microscopic structure of the Pt layer through electrochemical routes: (a) CO-stripping, (b) calculated ESA (triangle) and Pt coverage (sphere) of the synthesized Au@Pt NWs and Pt NWs. (c,d) ESA normalized activity in FA and MeOH electrooxidation.

charge transfer from 2,6-DMPI to Au through $\mathrm{Au}-\mathrm{CN}$ bond. As expected, with the gradual coating of $\mathrm{Pt}$ on $\mathrm{Au}$, the $\mathrm{Au}$ bound 2,6-DMPI related SERS is progressively substituted by that of Pt-bound 2,6-DMPI, i.e., peaks at 675, 1185, as well as a broad one at $2100-2160 \mathrm{~cm}^{-1}$. The almost complete silence of the Au-related SERS signal on 1.0 ML Pt-coated Au@Pt NWs evidence the formation of a pseudo Pt layer. Of note is that, besides the well identified peaks, a new broad shoulder located at $1750-2000 \mathrm{~cm}^{-1}$ was observed in Au@Pt NWs. We speculated that these peaks associated with $\mathrm{Pt}$ atoms display changed electronic state. After getting electrons for $\mathrm{Au}$ atoms, the $\pi$ back-donation of electrons to 2,6-DMPI through the Pt$\mathrm{CN}$ bond is enhanced, ${ }^{36}$ and the corresponding Raman signal will partly red-shift, especially for bridge and 3-fold hollow sitebound 2,6-DMPI (see discuss section in the Supporting Information).
The gradual replacement of $\mathrm{Au}$ surface with $\mathrm{Pt}$ skin was further substantiated by electrochemical experiments. Figure S9 shows the cyclic voltammograms (CVs) of $\mathrm{Au}$ and $\mathrm{Au} @ \mathrm{Pt}$ NWs in $\mathrm{HClO}_{4}$, which featured two waves at $\sim 0.9$ and $0.35 \mathrm{~V}$ versus $\mathrm{Ag} / \mathrm{AgCl}$ on the cathodic scan that arise from the reduction of $\mathrm{Au}$ oxide and $\mathrm{Pt}$ oxide, respectively. It should be noted that as long as the amount of Pt reaches $1 / 4 \mathrm{ML}$, the peak area for $\mathrm{Au}$ oxide reduction keeps increasing. This can be attributed to the stabilizing effect of the $\mathrm{Pt}$ layer to $\mathrm{Au}$ NWs. ${ }^{37,38}$ With the further increase of Pt amount to $1 / 2$ or 1.0 $\mathrm{ML}$, the peak of $\mathrm{Au}$ oxide reduction markedly decreased, signifying the stepwise substituting of Au surface with Pt skin. A CO-stripping experiment was further conducted to evaluate the electrochemical active surface area (ESA) of Pt (Figure 3a), as well as probe the atomic geometry of Pt atoms. On Pt NWs, the preabsorbed $\mathrm{CO}$ molecule strips at $0.67 \mathrm{~V}$, while after being coated on the Au surface as a submonolayer Pt (no more than 
$1 / 2 \mathrm{ML}$ ), this wave largely positive-shifted to $\sim 0.9 \mathrm{~V}$. Such high potential reveals the high binding energy for the Pt atom in $\mathrm{Au} @ \mathrm{Pt}$ NWs to CO, and thus symbolizes the existence of low coordinated Pt atoms. ${ }^{8,39,40}$ However, when 1.0 ML Pt was coated on Au NW surfaces, the CO-stripping peak became very broad. This broadening and downshift of the CO-stripping peak implies the decrease in $\mathrm{Pt}$ atom dispersity, or the formation of $\mathrm{Pt}$ assemblies. Moreover, calculated from the charge associated with $\mathrm{AuO}_{x}$ reduction and $\mathrm{CO}$-stripping (Figure $3 \mathrm{~b}$ and Table S1), the Pt coverage for $1 / 16,1 / 8,1 / 4$, $1 / 2$ and 1.0 ML Pt coated Au NWs is $0.13,0.14,0.23,0.49$ and 0.79 , respectively. The good match between theoretical data and experiment result, especially for $1 / 8,1 / 4$ and $1 / 2 \mathrm{ML} \mathrm{Pt}$, indicates that $\mathrm{Pt}$ atoms are present as a monolayer on the $\mathrm{Au}$ surface.

The microscopic structure of Pt atoms in $\mathrm{Au} @ \mathrm{Pt} \mathrm{NWs}$, i.e., highly dispersed $\mathrm{Pt}$ atoms or Pt ensembles (with three or more continuous atoms), was further explored by the electrooxidation of formic acid (FA) and methanol $(\mathrm{MeOH})$. It is well-known that highly dispersed Pt atoms display high activity in electrooxidation of FA via the direct dehydrogenation pathway, while being completely inactive in $\mathrm{MeOH}$ electrooxidation reaction. ${ }^{8,39,40}$ In contrast, the Pt ensemble has moderate affinity for $\mathrm{CO}$, is prone to oxidize FA through the intermediates pathway, and can also act as active site for $\mathrm{MeOH}$ oxidation. As sketched in Figure 3c,d and Table S1, all Au@Pt NWs show high activity in FA electrooxidation via the direct pathway, about 3-15 times more active than $\mathrm{Pt}$ NWs. However, except for 1.0 ML Pt coated Au@Pt NWs, the synthesized Au@Pt NWs are totally inactive in $\mathrm{MeOH}$ oxidation. These results suggested that the $\mathrm{Pt}$ atoms are highly dispersed.

We finally briefly discuss the mechanism for the growth of a foreign metal shell on Au NW surfaces. As is demonstrated by the control experiment, if injecting their precursors into $\mathrm{Au}$ NW dispersion quickly, Pt and Ag NPs, rather than nanoshells, were formed (FigureS4, S11), and this notion is further supported by the strong absorbance near $400 \mathrm{~nm}$ in a $\mathrm{AgNO}_{3}$ injected $\mathrm{Au} \mathrm{NW}$ dispersion (Figure S12). Thus, slow addition of metal precursor to the reaction solution to modulate the reduction kinetics, and thus regulating the nanocrystal growth model, is essential to the shell formation. According to the heterogeneous nucleation and growth theory, low concentration of metal precursor, and therefore low concentration of reduced metal atoms in the reaction solution, are prone to adsorb/deposit on existing NWs as dispersed atoms rather than form separated nucleus. The question remains, how do these atoms deposit on Au NW surfaces: by the layered growth mode (Frank-van der Merwe, F-M mode), the island growth mode (Volmer-Weber, V-W mode), or the layer-plus-island mode (Stranski-Krastanow, S-K mode) ${ }^{39}$ It is well acknowledged that the atomic radius, bond dissociation energy, and electronegativity are the key elements that determine the growth pattern of shell metal. ${ }^{17}$ Since Pt $(306.7 \mathrm{~kJ} / \mathrm{mol})$ has a higher bond dissociation energy than $\mathrm{Au}(226.2 \mathrm{~kJ} / \mathrm{mol})$, it seems that the stepwise growth of a Pt layer on the Au surface may follow the island mode. For example, a Pt island is formed on the Au electrode when the theoretical amount of Pt is as low as $0.31 \mathrm{ML},{ }^{39}$ and dendritic Pt was epitaxially coated on the $\mathrm{Au}$ nanoparticle surface by seed-mediated growth. ${ }^{17}$ However, in our case, electrochemistry experiment shows that as long as the coverage of $\mathrm{Pt}$ reached $0.50 \mathrm{ML}$, no Pt island formed, so the growth of Pt shell must be following the $\mathrm{S}-\mathrm{K}$ mode. The key point is, which factor, the surfactant or inorganic ion, alters the growth pattern of $\mathrm{Pt}$ on the $\mathrm{Au}$ surface?

Combining with our previous study on the interaction between TX-114 and noble metal surface, ${ }^{29}$ we believe that the presence of TX-114 plays a key role in forming Pt shell on $\mathrm{Au}$ surface. As is visualized by NMR experiments, for the existence of free d orbit, TX-114 interacts strongly with Pt atoms through $\pi-\mathrm{d}$ interaction, which should weaken the interaction among $\mathrm{Pt}$ atoms. Moreover, the charge-transfer between $\mathrm{Au}$ and $\mathrm{Pt}$ strengthen the $\mathrm{Au}-\mathrm{Pt}$ bond, thus the attachment of $\mathrm{Pt}$ atoms to $\mathrm{Au}$ surface is more thermodynamically favorable than forming a $\mathrm{Pt}-\mathrm{Pt}$ bond. While derived by the formation of more $\mathrm{Pt}-\mathrm{Au}$ bonds, before a critical $\mathrm{Pt}$ coverage is reached, the newly deposited $\mathrm{Pt}$ atom is apt to exist as a dispersed atom rather than a Pt assembly (Figure S9-S13).

The idea that the absorption of TX-114 on metal atoms changes the interaction among metal atoms is further supported by coating $\mathrm{Rh}$ and $\mathrm{Pd}$ on $\mathrm{Pt}$ NWs by a similar method. Both $\mathrm{Rh}$ and $\mathrm{Pd}$ have smaller atomic radii than $\mathrm{Pt}$ atoms, and lower or same electronegativity with $\mathrm{Pt}$; the bond dissociation energy for $\mathrm{Rh}-\mathrm{Rh}(235.85 \mathrm{~kJ} / \mathrm{mol})$ is larger than the $\mathrm{Pd}-\mathrm{Pd}$ bond (>136 kJ/mol). As $\mathrm{Rh}$ has three unoccupied $\mathrm{d}$-orbits, while all d-orbits in Pd atoms are occupied, the $\pi-\mathrm{d}$ interaction is strong for $\mathrm{Rh}$ but weak for $\mathrm{Pd}$ atom. Therefore $\mathrm{Rh}$ is capable of coating on Pt NW surface as a nanoshell, while Pd just forms a nanoisland on the Pt surface (Table S2).

The applicability of the developed nanostructure for SERS monitoring of catalyzed reactions was studied with Pt catalyzed p-NTP reduction. To this end, a $\sim 250 \mathrm{~nm}$ thick Au@Pt NW film was deposited on a transparent $\mathrm{SiO}_{2}(250 \mu \mathrm{m}$ in thickness $)$ slide. Figures 4a,b and S14 display the FESEM image of Au@Pt NW film with $1 / 2 \mathrm{ML}$ Pt. Thanks to the effectiveness of the Pt layer in suppressing the coarsening of $\mathrm{Au}$ nanostructures, after being deposited on a $\mathrm{SiO}_{2}$ slide, $^{37}$ no alteration to the morphology of Au@Pt NWs occurred, and the deposited NWs formed a uniform and crack-free film. Figure S15 displays the dark field scattering spectrum of deposited Au and Au@Pt NW film. The much stronger scattering in the NIR (ca. $785 \mathrm{~nm}$ ) than the visible region (ca. 532) was mainly due to the SPR induced electromagnetic field. In accordance with this trend, under the excitation of $785 \mathrm{~nm}$ laser, NW films show EF in the range of $1.3 \times 10^{5}$ to $1.6 \times 10^{3}$, which is much larger than under 633 or $532 \mathrm{~nm}$ laser excitation. We believe this Raman enhancement mainly associated with the nanogaps that decrease to $\sim 1.0 \mathrm{~nm}$ from the pile up of hundreds of NWs (Figure S16-17 and Table S3). However, these nanogaps get wider with the formation of the Pt layer, which can be explained by the increased steric hindrance among TX-114 molecules that were adsorbed on $\mathrm{Pt}$ atoms more strongly than that on $\mathrm{Au}$ atoms. As the formation of NW film results from the desorption of TX-114 from Au atoms, the residue TX-114 on $\mathrm{Pt}$ atoms increases the width of the nanogap. Meanwhile, the damper effect of the Pt layer on the SPR property of Au NWs may also lower the EF in Au@Pt NW film (Figure S18). Besides the satisfactory EF, the deposited film also showed exceptionally good reproducibility due to their good surface uniformity, and the RSD of the peak height at $1340 \mathrm{~cm}^{-1}$ is less than $7 \%$ in a randomly selected $0.2 \mathrm{~cm} \times 0.2 \mathrm{~cm}$ area (Figure S19-20). These features make such material an ideal platform for quantitative SERS surveying of chemical processes, either by recording the Raman spectra at selected intervals (ex situ), or by acquiring the spectra under operando conditions (in situ). 


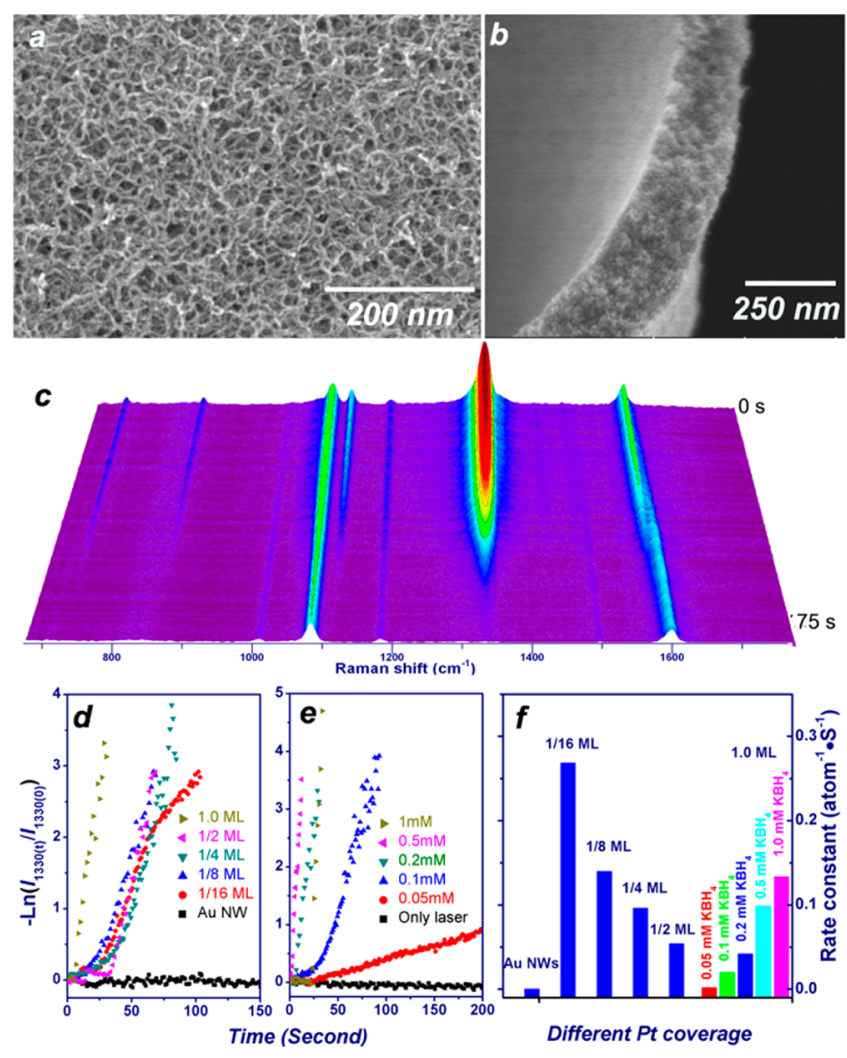

Figure 4. (a,b) FESEM images of the fabricated Au@Pt NPF, (c) 3D SERS mapping recorded on $p$-NTP loaded Au@Pt NW film (150 spectra, $0.5 \mathrm{~s} /$ spectrum). (d-f) Rate constants for the reduction of $p$ NTP with KBH4 and catalyzed by Au@Pt NWs with different Pt coverage (based on the intensity of $1340 \mathrm{~cm}^{-1}$ ).

After loading with $p$-NTP, the slide was stuck onto a lab-built reactor, with NW film exposes to the cavity of the reactor. During the reaction, the enhanced Raman spectra from the same location were consecutively collected (Figure S21). Such configuration first enables all the SERS measurements fulfilled in water phase, thus the possible photothermal/plasmonic effect can be suppressed, and the second makes the reaction isolated from air to prevent the formation of artificial reaction intermediate. $^{41,42}$ As sketched in the $3 \mathrm{D}$ reaction trace (Figure 4c), upon the addition of $0.2 \mathrm{mM} \mathrm{KBH}_{4}$, the dominant Raman feature of $p$-NTP, peaks at $\sim 1340$ and $\sim 1570 \mathrm{~cm}^{-1}$, quickly diminished in $75 \mathrm{~s}$, while a new band at $1590 \mathrm{~cm}^{-1}$ appeared, which can be assigned to the formation of $p$-ATP. These results demonstrated the performance of $\mathrm{Au} @ \mathrm{Pt} \mathrm{NWs}$ in in situ chemical process monitoring, as well as the high catalytic activity of Au@Pt NWs. It is worth noting that in the whole process no SERS signal associated with 4,4'-dimercaptoazobenzene (DMAB), a plausible intermediate of this reaction, was observed, and all the acquired spectra can be deconvoluted into the Raman spectrum of $p$-ATP and $p$-NTP. However, DMBA can be observed in ex situ experiment (Figure S22). Considering the high possibility of DMBA generation from the photoreduction of $p$-NTP or the photooxidation of $p$ ATP, ${ }^{41,43,44}$ we attribute the detected DMBA to the photorelated process, rather than considering it as an intermediate in $\mathrm{KBH}_{4}$ reduction of $p$-NTP. To verify this, we recorded the time-dependent SERS spectra on $p$-NPT, $p$-ATP, as well as both $p$-NTP and $p$-NTP loaded Au@Pt NW film upon continuous laser excitation. As witnessed in Figure S23-26, when the reactor was exposed to air, DMBA was generated from $p$-NTP and $p$-ATP, even under the illumination of 785 $\mathrm{nm}$ laser $(0.5 \mathrm{~mW}$, reaction under the excitation of 633 or 532 $\mathrm{nm}$ leaser is much faster); while after immersed in water, the formation of DMBA was largely suppressed on Au NPF and almost diminished on $\mathrm{Au} @ \mathrm{Pt}$ NW film, thus providing sound evidence for the notion that the detected DMBA is more likely to be generated during ex-situ measurement process. This result manifests the superiority of operando monitoring in provision of virginal reaction detail, and the usefulness of Au@Pt NWs in such a task.

Figure 4 d,e shows the plots of $-\ln \left(I_{1340(t)} / I_{1340(0)}\right)$ as a function of reaction time for different Pt layer-coated Au@Pt NWs, and 1.0 ML Pt coated $\mathrm{Au} @ \mathrm{Pt} \mathrm{NWs}$ in various concentrations of $\mathrm{KBH}_{4}$, where $I_{1340(\mathrm{t})}$ and $I_{1340(0)}$ represent the SERS intensity at $1340 \mathrm{~cm}^{-1}$ at different time. The good linearity suggests this process is first-ordered. Taking into account the density of $p$-NPT on NW surface $(\sim 6.0$ molecule $\left.\mathrm{nm}^{-2}\right),{ }^{45}$ the calculated apparent rate constant for $1 / 16,18 /, 1 /$ 4, 1/2 and 1.0 ML Pt coated Au@Pt NWs is 0.27, 0.14, 0.096, 0.054 , and 0.042 (per Pt atom per S) ${ }^{-1}$ (Figures $4 \mathrm{f}$ and S27), respectively. The activity of highly dispersed $\mathrm{Pt}$ atom is shown to be 6 times higher than that of dense Pt layer, which again confirms the high activity and utility of highly dispersed $\mathrm{Pt}$ atoms. Interestingly, the reaction pathway on 1/16 ML Ptcoated Au@Pt can be divided into two parts. Considering that $\mathrm{Pt}$ atoms are solely active sites for $p$-NPT reduction, while both $\mathrm{Au}$ and Pt adsorbed $p$-NTP contribute to the recorded SERS spectra. So we attribute the fast reaction stage to the reduction of $p$-NTP on Pt atom, and as well as these molecules that in adjacent sites and diffuse to $\mathrm{Pt}$ atoms easily, while the slower one may stem from $\mathrm{Au}$ atom far from $\mathrm{Pt}$ atoms and transferred to Pt sluggishly.

In conclusion, ultrathin Pt shells, either as highly dispersed atoms or pseudo monolayers, were successfully coated on ultrathin $\mathrm{Au}$ NWs via a direct and fast protocol. The presence of TX-114 is believed to lower the interaction energy between the $\mathrm{Pt}$ atoms, and makes the growth of a Pt layer on a $\mathrm{Au}$ surface thermodynamically favorable. The synthesized Au@Pt NWs offered a huge electromagnetic field for enhancing the Raman scattering on the Pt surface; in addition, the underlined $\mathrm{Au}$ NWs significantly improved the dispersity of $\mathrm{Pt}$ atoms, disturbed their electronic state, and thus markedly enhanced their catalytic activity. Employing the developed Au@Pt NWs for operando SERS study of the catalytic reaction process of $p$ NTP, a frequently observed reaction intermediate in ex-situ experiments, DMBA, was excluded. This coating strategy can be extended to the coating of other transit metals, like Pd, Ag, and $\mathrm{Rh}$ on $\mathrm{Au}$ surfaces and be used to study reaction catalyzed by these metals (Figure S28-29). On the other hand, our method also gives a new way to synthesize nanocatalyst with high efficient, especially for supported highly dispersed precious metal atoms. ${ }^{46,47}$ This will furnish a promising solution to technological problems like the limited availability and the high price of Pt. As we were finalizing this manuscript, we noticed that Han et al reported the reduction of $p$-NTP to $p$-ATP with $\mathrm{H} 2$, which is catalyzed by $\mathrm{Au} @ \mathrm{PdAu}$ nanorod, is also a 4,4'DMBA independent reaction, ${ }^{48}$ and recently $B$ ehm et al reported a kinetic limitation based method for epitaxial electrodeposition of Pt layer on Au substrate. ${ }^{49}$ 


\section{ASSOCIATED CONTENT}

\section{S Supporting Information}

Procedure for other bimetal NWs synthesis, control experiment, characterization, details for electrochemistry and SERS experiments, extra figures and tables, and deep interpretation of these data. This material is available free of charge via the Internet at http://pubs.acs.org.

\section{AUTHOR INFORMATION}

\section{Corresponding Author}

*E-mail: jfliu@rcees.ac.cn.

\section{Notes}

The authors declare no competing financial interest.

\section{ACKNOWLEDGMENTS}

We acknowledge the two anonymous reviewers for their constructive comments and suggestions. This work was financially supported by the National Basic Research Program of China (2011CB936001), the National Natural Science Foundation of China $(21025729,21207144)$, and the Research Device Development Project of Chinese Academy of Sciences (YZ201147)

\section{REFERENCES}

(1) Serpell, C. J.; Cookson, J.; Ozkaya, D.; Beer, P. D. Core@Shell Bimetallic Nanoparticle Synthesis via Anion Coordination. Nat. Chem. 2011, 3, 478-483.

(2) Tian, Z. Q.; Ren, B.; Li, J. F.; Yang, Z. L. Expanding Generality of Surface-Enhanced Raman Spectroscopy with Borrowing SERS Activity Strategy. Chem. Commun. 2007, 3514-3534.

(3) Heck, K. N.; Janesko, B. G.; Scuseria, G. E.; Halas, N. J.; Wong, M. S. Observing Metal-Catalyzed Chemical Reactions in Situ Using Surface-Enhanced Raman Spectroscopy on Pd-Au Nanoshells. J. Am. Chem. Soc. 2008, 130, 16592-16600.

(4) Xie, W.; Herrmann, C.; Kompe, K.; Haase, M.; Schlucker, S. Synthesis of Bifunctional $\mathrm{Au} / \mathrm{Pt} / \mathrm{Au}$ Core/Shell Nanoraspberries for in Situ SERS Monitoring of Platinum-Catalyzed Reactions. J. Am. Chem. Soc. 2011, 133, 19302-19305.

(5) Buurmans, I. L. C.; Weckhuysen, B. M. Heterogeneities of Individual Catalyst Particles in Space and Time as Monitored by Spectroscopy. Nat. Chem. 2012, 4, 873-886.

(6) Kim, H.; Kosuda, K. M.; Van Duyne, R. P.; Stair, P. C. Resonance Raman and Surface- and Tip-Enhanced Raman Spectroscopy Methods to Study Solid Catalysts and Heterogeneous Catalytic Reactions. Chem. Soc. Rev. 2010, 39, 4820-4844.

(7) Morozan, A.; Jousselme, B.; Palacin, S. Low-Platinum and Platinum-Free Catalysts for the Oxygen Reduction Reaction at Fuel Cell Cathodes. Energ. Environ. Sci. 2011, 4, 1238-1254.

(8) Maroun, F.; Ozanam, F.; Magnussen, O. M.; Behm, R. J. The Role of Atomic Ensembles in the Reactivity of Bimetallic Electrocatalysts. Science 2001, 293, 1811-1814.

(9) Kyriakou, G.; Boucher, M. B.; Jewell, A. D.; Lewis, E. A.; Lawton, T. J.; Baber, A. E.; Tierney, H. L.; Flytzani-Stephanopoulos, M.; Sykes, E. C. H. Isolated Metal Atom Geometries as a Strategy for Selective Heterogeneous Hydrogenations. Science 2012, 335, 1209-1212.

(10) Zhang, G. R.; Zhao, D.; Feng, Y. Y.; Zhang, B. S.; Su, D. S.; Liu, G.; Xu, B. Q. Catalytic Pt-on-Au Nanostructures: Why Pt Becomes More Active on Smaller Au Particles. ACS Nano 2012, 6, 2226-2236.

(11) Henning, A. M.; Watt, J.; Miedziak, P. J.; Cheong, S.; Santonastaso, M.; Song, M. H.; Takeda, Y.; Kirkland, A. I.; Taylor, S. H.; Tilley, R. D. Gold-Palladium Core-Shell Nanocrystals with Size and Shape Control Optimized for Catalytic Performance. Angew. Chem., Int. Ed. 2013, 52, 1477-1480.

(12) Zhang, J.; Sasaki, K.; Sutter, E.; Adzic, R. R. Stabilization of Platinum Oxygen-Reduction Electrocatalysts Using Gold Clusters. Science 2007, 315, 220-222.
(13) Chen, M. S.; Kumar, D.; Yi, C. W.; Goodman, D. W. The Promotional Effect of Gold in Catalysis by Palladium-Gold. Science 2005, 310, 291-293.

(14) Roduner, E. Size Matters: Why Nanomaterials are Different. Chem. Soc. Rev. 2006, 35, 583-592.

(15) Joseph, V.; Engelbrekt, C.; Zhang, J.; Gernert, U.; Ulstrup, J.; Kneipp, J. Characterizing the Kinetics of Nanoparticle-Catalyzed Reactions by Surface-Enhanced Raman Scattering. Angew. Chem., Int. Ed. 2012, 51, 7592-7596.

(16) Mazumder, V.; Chi, M. F.; More, K. L.; Sun, S. H. Synthesis and Characterization of Multimetallic $\mathrm{Pd} / \mathrm{Au}$ and $\mathrm{Pd} / \mathrm{Au} / \mathrm{FePt}$ Core/Shell Nanoparticles. Angew. Chem., Int. Ed. 2010, 49, 9368-9372.

(17) Fan, F. R.; Liu, D. Y.; Wu, Y. F.; Duan, S.; Xie, Z. X.; Jiang, Z. Y.; Tian, Z. Q. Epitaxial Growth of Heterogeneous Metal Nanocrystals: From Gold Nano-octahedra to Palladium and Silver Nanocubes. J. Am. Chem. Soc. 2008, 130, 6949-6951.

(18) Lee, W. R.; Kim, M. G.; Choi, J. R.; Park, J. I.; Ko, S. J.; Oh, S. J.; Cheon, J. Redox-Transmetalation Process as a Generalized Synthetic Strategy for Core-Shell Magnetic Nanoparticles. J. Am. Chem. Soc. 2005, 127, 16090-16097.

(19) Koenigsmann, C.; Santulli, A. C.; Gong, K. P.; Vukmirovic, M. B.; Zhou, W. P.; Sutter, E.; Wong, S. S.; Adzic, R. R. Enhanced Electrocatalytic Performance of Processed, Ultrathin, Supported PdPt Core-Shell Nanowire Catalysts for the Oxygen Reduction Reaction. J. Am. Chem. Soc. 2011, 133, 9783-9795.

(20) Sasaki, K.; Naohara, H.; Cai, Y.; Choi, Y. M.; Liu, P.; Vukmirovic, M. B.; Wang, J. X.; Adzic, R. R. Core-Protected Platinum Monolayer Shell High-Stability Electrocatalysts for Fuel-Cell Cathodes. Angew. Chem., Int. Ed. 2010, 49, 8602-8607.

(21) Mallik, K.; Mandal, M.; Pradhan, N.; Pal, T. Seed Mediated Formation of Bimetallic Nanoparticles by UV Irradiation: A Photochemical Approach for the Preparation of "Core-Shell" Type Structures. Nano Lett. 2001, 1, 319-322.

(22) Lee, Y. W.; Kim, M.; Kim, Z. H.; Han, S. W. One-Step Synthesis of Au@Pd Core-Shell Nanooctahedron. J. Am. Chem. Soc. 2009, 131, 17036-17038.

(23) Kim, K.; Kim, K. L.; Shin, K. S. Co-Reduced Ag/Pd Bimetallic Nanoparticles: Surface Enrichment of Pd Revealed by Raman Spectroscopy. J. Phys. Chem. C 2011, 115, 14844-14851.

(24) Wang, D.; Xin, H. L.; Hovden, R.; Wang, H.; Yu, Y.; Muller, D. A.; Disalvo, F. J.; Abruna, H. D. Structurally Ordered Intermetallic Platinum-Cobalt Core-Shell Nanoparticles with Enhanced Activity and Stability as Oxygen Reduction Electrocatalysts. Nat. Mater. 2012, $12,81-87$.

(25) Lee, S. J.; Moskovits, M. Remote Sensing by Plasmonic Transport. J. Am. Chem. Soc. 2012, 134, 11384-11387.

(26) Liu, J. W.; Wang, J. L.; Huang, W. R.; Yu, L.; Ren, X. F.; Wen, W. C.; Yu, S. H. Ordering Ag Nanowire Arrays by a Glass Capillary: A Portable, Reusable and Durable SERS Substrate. Sci. Rep. 2012, 2, 987.

(27) Lal, S.; Hafner, J. H.; Halas, N. J.; Link, S.; Nordlander, P. Noble Metal Nanowires: From Plasmon Waveguides to Passive and Active Devices. Acc. Chem. Res. 2012, 45, 1887-1895.

(28) Feng, H. J.; Yang, Y. M.; You, Y. M.; Li, G. P.; Guo, J.; Yu, T.; Shen, Z. X.; Wu, T.; Xing, B. G. Simple and Rapid Synthesis of Ultrathin Gold Nanowires, Their Self-assembly and Application in Surface-Enhanced Raman Scattering. Chem. Commun. 2009, 19841986.

(29) Liu, R.; Liu, J. F.; Jiang, G. B. Use of Triton X-114 as a Weak Capping Agent for One-Pot Aqueous Phase Synthesis of Ultrathin Noble Metal Nanowires and a Primary Study of Their Electrocatalytic Activity. Chem. Commun. 2010, 46, 7010-7012.

(30) Xu, Z. C.; Hou, Y. L.; Sun, S. H. Magnetic Core/Shell $\mathrm{Fe}_{3} \mathrm{O}_{4} / \mathrm{Au}$ and $\mathrm{Fe}_{3} \mathrm{O}_{4} / \mathrm{Au} / \mathrm{Ag}$ Nanoparticles with Tunable Plasmonic Properties. J. Am. Chem. Soc. 2007, 129, 8698-8699.

(31) Gao, C. B.; Zhang, Q.; Lu, Z. D.; Yin, Y. D. Templated Synthesis of Metal Nanorods in Silica Nanotubes. J. Am. Chem. Soc. 2011, 133, 19706-19709. 
(32) Zhang, K.; Xiang, Y. J.; Wu, X. C.; Feng, L. L.; He, W. W.; Liu, J. B.; Zhou, W. Y.; Xie, S. S. Enhanced Optical Responses of Au@Pd Core/Shell Nanobars. Langmuir 2009, 25, 1162-1168.

(33) Wang, H.; Wang, Y.; Zhu, Z.; Sapi, A.; An, K.; Kennedy, G.; Michalak, W. D.; Somorjai, G. A. Influence of Size-Induced Oxidation State of Platinum Nanoparticles on Selectivity and Activity in Catalytic Methanol Oxidation in the Gas Phase. Nano Lett. 2013, 13, 2976-9.

(34) Kim, K.; Kim, K. L.; Shin, K. S. Co-Reduced Ag/Pd Bimetallic Nanoparticles: Surface Enrichment of Pd Revealed by Raman Spectroscopy. J. Phys. Chem. C 2011, 115, 14844-14851.

(35) Liu, R.; Liu, J. F.; Zhou, X. X.; Sun, M. T.; Jiang, G. B. Fabrication of a $\mathrm{Au}$ Nanoporous Film by Self-Organization of Networked Ultrathin Nanowires and Its Application as a SurfaceEnhanced Raman Scattering Substrate for Single-Molecule Detection. Anal. Chem. 2011, 83, 9131-9137.

(36) Kim, N. H.; Kim, K. Adsorption Characteristics of Arylisocyanide on $\mathrm{Au}$ and Pt Electrode Surfaces: Surface-Enhanced Raman Scattering Study. J. Phys. Chem. B 2006, 110, 1837-1842.

(37) Snyder, J.; Asanithi, P.; Dalton, A. B.; Erlebacher, J. Stabilized Nanoporous Metals by Dealloying Ternary Alloy Precursors. Adv. Mater. 2008, 20, 4883-4885.

(38) Biener, M. M.; Biener, J.; Wichmann, A.; Wittstock, A.; Baumann, T. F.; Baumer, M.; Hamza, A. V. ALD Functionalized Nanoporous Gold: Thermal Stability, Mechanical Properties, and Catalytic Activity. Nano Lett. 2011, 11, 3085-90.

(39) Du, B. C.; Tong, Y. Y. A Coverage-Dependent Study of Pt Spontaneously Seposited onto $\mathrm{Au}$ and Ru Surfaces: Direct Experimental Evidence of the Ensemble Effect for Methanol Electrooxidation on Pt. J. Phys. Chem. B 2005, 109, 17775-17780.

(40) Cuesta, A. At Least Three Contiguous Atoms Are Necessary for CO Formation During Methanol Electrooxidation on Platinum. J. Am. Chem. Soc. 2006, 128, 13332-13333.

(41) Huang, Y. F.; Zhu, H. P.; Liu, G. K.; Wu, D. Y.; Ren, B.; Tian, Z. Q. When the Signal Is Not from the Original Molecule to $\mathrm{Be}$ Detected: Chemical Transformation of para-Aminothiophenol on $\mathrm{Ag}$ during the SERS Measurement. J. Am. Chem. Soc. 2010, 132, 92449246.

(42) Xu, P.; Kang, L. L.; Mack, N. H.; Schanze, K. S.; Han, X. J.; Wang, H. L. Mechanistic Understanding of Surface Plasmon Assisted Catalysis on a Single Particle: Cyclic Redox of 4-Aminothiophenol. Sci. Rep. 2013, 3, 2997.

(43) Sun, M. T.; Zhang, Z. L.; Zheng, H. R.; Xu, H. X. In-Situ Plasmon-Driven Chemical Reactions Revealed by High Vacuum TipEnhanced Raman Spectroscopy. Sci. Rep. 2012, 2, 647.

(44) Sun, M. T.; Xu, H. X. A Novel Application of Plasmonics: Plasmon-Driven Surface-Catalyzed Reactions. Small 2012, 8, 27772786.

(45) Hinterwirth, H.; Kappel, S.; Waitz, T.; Prohaska, T.; Lindner, W.; Lammerhofer, M. Quantifying Thiol Ligand Density of SelfAssembled Monolayers on Gold Nanoparticles by Inductively Coupled Plasma-Mass Spectrometry. ACS Nano 2013, 7, 1129-1136.

(46) Yang, X.-F.; Wang, A.; Qiao, B.; Li, J.; Liu, J.; Zhang, T. SingleAtom Catalysts: A New Frontier in Heterogeneous Catalysis. Acc. Chem. Res. 2013, 46, 1740-1748.

(47) Qiao, B. T.; Wang, A. Q.; Yang, X. F.; Allard, L. F.; Jiang, Z.; Cui, Y. T.; Liu, J. Y.; Li, J.; Zhang, T. Single-atom Catalysis of CO Oxidation Using Pt-1/FeOx. Nat. Chem. 2011, 3, 634-641.

(48) Huang, J.; Zhu, Y.; Lin, M.; Wang, Q.; Zhao, L.; Yang, Y.; Yao, K. X.; Han, Y. Site-Specific Growth of Au-Pd Alloy Horns on Au Nanorods: A Platform for Highly Sensitive Monitoring of Catalytic Reactions by Surface Enhancement Raman Spectroscopy. J. Am. Chem. Soc. 2013, 135, 8552-8561.

(49) Fennell, J.; He, D.; Tanyi, A. M.; Logsdail, A. J.; Johnston, R. L.; Li, Z. Y.; Horswell, S. L. A Selective Blocking Method to Control the Overgrowth of $\mathrm{Pt}$ on Au Nanorods. J. Am. Chem. Soc. 2013, 135, 6554-61. 